\title{
An evaluation of estimation methods for determining addition in presbyopes
}

\section{Avaliação de diferentes métodos para determinar adição em présbitas}

Leonardo Catunda Bittencourt ${ }^{1}$, Milton Ruiz Alves², Daniel Oliveira Dantas ${ }^{3}$, Pablo Felipe Rodrigues ${ }^{4}$, Edson dos Santos-Neto ${ }^{5}$

\section{ABSTRACT}

Purpose: The optical correction of presbyopia must be handled individually. Our aim was to compare the methods used in addition to the refractive near vision, with the final addition used in presbyopic patients.

Methods: Eighty healthy subjects with a mean age of 49.7 years (range 40 to 60 years) were studied. Tentative near additions were determined using four different techniques: one-half amplitude accommodation with minus lenses (AAL); one-third accommodative demand with positive lens (ADL); balanced range of accommodation with minus and positive lenses (BRA) and crossed cylinder test with initial myopisation (CCT). The power of the addition was then refined to arrive at the final addition.

Results: The mean tentative near additions were lower than the final addition for ADL and BRA addition methods. The mean differences between tentative and final additions were low for all the tests examined (less than $0.25 \mathrm{D}$ ). The intervals between the $95 \%$ limits of agreement differed substantially and were always higher than $\pm 0.50 \mathrm{D}$

Conclusion: All the methods used displayed similar behavior and provided a tentative addition close to the final addition. The coefficient of agreements (COA) detected suggests that every tentative addition should be adjusted according to the particular needs of the patient.

Keywords: Accommodation, ocular; Eyeglasses; Presbyopia/therapy; Depth perception; Lenses

\section{RESUMO}

Objetivo: A correção óptica da presbiopia deve ser manejada individualmente. Nosso intuito é de comparar os métodos usados para calcular a adição na elaboração do grau para perto em pacientes présbitas.

Métodos: Oitenta pacientes com média de idade de 49,7 anos (intervalo de 40 a 60 anos) foram estudados. Adições provisórias foram determinadas usando quatro diferentes técnicas: metade da amplitude de acomodação com lentes negativas (AAL): um terco da demanda acomodativa com lentes positivas (ADL): média aritmética da acomodação usando lentes positivas e negativas (BRA); teste com o cilindro cruzado com miopização (CCT). O grau final foi refinado até chegar a graduação final da adição.

Resultados: A média das adições nos testes foram menores que as adições finais nos métodos $A D L$ e BRA. As diferenças médias entre os testes e o grau final foram baixas em todos os métodos (menores que $+0,25 \mathrm{D}$ ). Os intervalos entre os $95 \%$ dos limites da concordância diferenciaram substancialmentee foram todos maiores que $\pm 0.50 \mathrm{D}$. Conclusão: Todos os métodos usados demonstraram comportamentos similares e forneceram resultados bem próximos da adição final. O coeficiente de concordância (COA) detectado, sugere que todos os métodos utilizados devem ser ajustados de acordo com as necessidades do paciente.

Descritores: Acomodação ocular; Óculos; Presbiopia/terapia; Percepcão de profundidade; Lentes

\section{INTRODUCTION}

Presbyopia (from the Greek presbys, elder or old, and, -ops, eye) is a progressive condition where the ability to focus on near objects is gradually lost as part of the natural aging process ${ }^{(1)}$. Presbyopia tends to manifest itself around the age of 40 to 45 years, at an extremely productive stage in life and its inadequate correction will compromise a person's work performance with the economic loses that this entails ${ }^{(2)}$.

The optical correction of presbyopia must be handled individually. The amount of accommodation varies not only from person to person, but also from eye to eye. Therefore it is necessary to prescribe the weakest lenses which are tolerable for good and comfortable near vision in order to find harmony between the processes of accommodation and convergence ${ }^{(3)}$. Normally, a tentative addition is established first and this is then adjusted to obtain the final addition ${ }^{(4)}$. In the case of correction it is necessary to respect working distance to which a person has to adapt their vision and which is very important in various professions. An error in reading addition is one of the most common causes of patients' unhappiness with their new spectacles ${ }^{(5)}$. For example, when the range of clear vision is not well determined, patients may complain that the new spectacles are fine for reading, but that they are now unable to see a computer screen ${ }^{(6)}$. A classic clinical rule, used by most ophthalmologists, is that the patient should be able to support up to half of its full range of amplitude of accommodation $(A A)^{(7)}$.

Many variables affecting accommodative testing are difficult to control, including illumination, depth of focus, target size, contrast, visual angle, lens affectiveness, monocular and binocular cues, kines-

Submitted for publication: August 21, 2012

Accepted for publication: May 21, 2013

Study carried out at Hospital das Clínicas da Faculdade de Medicina, Universidade de São Paulo USP - São Paulo (SP), Brazil.

Physician, Hospital das Clínicas da Faculdade de Medicina, Universidade de São Paulo - USP - São Paulo (SP), Brazil.

2 Physician, Setor de Córnea e Doenças Externas do Hospital das Clínicas da Faculdade de Medicina, Universidade de São Paulo - USP - São Paulo (SP), Brazil.

Universidade de São Paulo - USP - São
${ }^{3}$ Statistician, São Paulo (SP), Brazil.

Physician, Setor de Córnea e Doenças Externas no Hospital das Clínicas da Faculdade de Medicina, Universidade de São Paulo - USP - São Paulo (SP), Brazil.

Physician, Hospital das Clínicas da Faculdade de Medicina, Universidade de São Paulo - USP - São Paulo (SP), Brazil.

Funding: No specific financial support was available for this study.

Disclosure of potential conflicts of interest: L.C.Bittencourt, None; M.R.Alves, None; D.O.Dantas, None; P.F.Rodrigues, None; E.Santos-Neto, None.

Correspondence address: Leonardo Catunda Bittencourt. Rua Loefgren, 441 - Apto. 153 - São Paulo (SP) - 04040-030 - Brazil - E-mail: leocatunda@gmail.com

Número do projeto no comitê de ética: 0821/10 HCFMUSP. 
thetic feedback, and the rate at which accommodative demand is changed during testing ${ }^{(8)}$. We feel it would be more reasonable to use the method that provides the tentative addition closest to the final addition. It is felt that it would accelerate the entire evaluation process. This study was designed to compare final addition values with the tentative additions obtained using the tests: one-half amplitude accommodation with minus lenses (AAL); one-third accommodative demand with positive lens (ADL); balanced range of accommodation with minus and positive lenses (BRA) and crossed cylinder test with initial myopisation (CCT).

\section{METHODS}

An observational, cross-section study was carried out. The research followed the tenets of the Declaration of Helsinki, and Institutional Review Board approval was obtained. All patients were informed about the purpose of the study and gave informed consent before inclusion. Patients were sequentially evaluated from February to November 2011. The age range of the subjects was 40 to 60 years (mean: 49.7, standard deviation: \pm 5.0 years). Fifty (62.5\%) patients were women and thirty (37.5\%) were men. The spherical refractive error ranged from -5.75 to $+5.00 \mathrm{D}$ with up to $-1.50 \mathrm{D}$ of astigmatism.

All patients required addition; and presented corrected monocular visual acuity (VA) greater than or equal to 6/7.5 at distance and near; anisometropy less than 1.50 D; no binocular problems; no history of refractive surgery, strabismus or amblyopia; no ocular pathology; no systemic disease that could affect accommodation, fusional vergences and/or ocular motility; and no medication likely to have side effects on accommodation and/or on fusional vergences. All the patients were submitted to the four different methods.

Demographic and clinical data were obtained, including data of birth and gender. Each subject underwent a comprehensive ophthalmologic examination including review of medical history, subjective refraction followed by binocular balancing, with Snellen optotypes presented at 6 meters, best correct visual acuity, slit-lamp biomicroscopy, ocular tonometry and fundoscopic examination. The subjective refractions were conducted to maximize the amount of positive sphere and minimize the amount of negative sphere without compromising distance visual acuity. Astigmatism was adjusted using the Jackson cross-cylinder. All the procedures used to determine tentative addition were performed in random order. The final addition for a $40 \mathrm{~cm}$ working distance was established for each patient by adjusting the tentative addition (AdT) obtained using one to the four methods selected at random:

\section{AAL Method - one-half amplitude accommodation (AA) WITH MINUS LENSES}

This procedure assumes that the prescription of addition should not use more than one-half of the total amplitude, the working distance in this study was $40 \mathrm{~cm}$, so the tentative addition value was calculated as $2.50 \mathrm{D}-1 / 2(\mathrm{AA})$, where $A A$ is the mean amplitude of accommodation between both eyes. To measure the AA, the subject was instructed to read the fine print on the nearpoint test card, placed at $40 \mathrm{~cm}$, while the accommodative demand was increased using minus lens in $0.25 \mathrm{D}$ steps by making a conscious accommodative effort.

\section{ADL Method - one-thiRd accommodative demand (AD) WITH POSITIVE LENS}

To measure the $A D$, with distance refraction in the phoropter and the nearpoint test card at $40 \mathrm{~cm}$, the subject was instructed to read the fine print on the test card. Then, plus lenses in 0.25 steps were added until the fine print on test card become clear $(L)$, so the AD was calculated as $2.50 \mathrm{D}-\mathrm{L}$, and the tentative addition value was calculated as $1 / 3 A D+L$.

\section{BRA Method - balanced RANGe of accommodation WITH MINUS AND POSITIVE LENSES}

This procedure assumes that the prescription of addition is to place the dioptric midpoint of the range of clear vision at the patient's customary near working distance. The dioptric midpoint was determined, with the patient's distance refraction in the phoropter and the near point test card at $40 \mathrm{~cm}$, by adding plus power lenses binocularly until the subject was no longer able to read the fine print on the test card, and by adding minus power lenses until the patient was no longer able to read the fine print, so the tentative addition value was calculated as the arithmetical media of these values.

\section{CCT Method - CROSSEd CyLinder test WITH INITIAL Myopisation}

A cross-grid target was placed on the near point rod of the phoropter at the patient's working distance, in this study at a $40 \mathrm{~cm}$, and the crossed cylinder (with the minus axis vertical) was positioned before both eyes. With the distance correction in place, were added plus lenses until the vertical lines on the target become as clear and dark as the horizontal lines, this was the tentative addition value.

The data were analyzed using the Analyze-it program for Microsoft Excel (Leeds, UK. See http://www.analyse-it.com statistics program) ${ }^{(6)}$. The level of agreement between the different tentative addition tests and the prescribed addition, or reference addition, was estimated using the Bland-Altman method ${ }^{(9,10)}$. Correlation is normally used to evaluate the agreement between two methods. The problem of correlation is that it is high when the points of the scatter plot fall on any straight line with positive derivative ${ }^{(6)}$. The factors determined were the mean difference (Bias), the standard deviation (SD), the coefficient of agreement (COA= $1.96 \times$ SD) and the limits of agreement at the $95 \%$ level (Bias \pm COA). The t-test for paired samples was also used to establish the significance of the differences. The level of significance was set at $p<0.05$.

\section{RESULTS}

Table 1 provides data on the level of agreement between each of the tests used to determine tentative addition in presbyopes and the final addition. The mean differences between tentative and final additions were low (less than $0.25 \mathrm{D}$ ) and the coefficients of agreement are moderately high in clinical terms, as they always exceeded 0.50 D.

Figure 1 shows plots for each subject of the difference between the tentative addition (AdT) and the final addition (AdF) versus the mean of the two additions. The lines at $U$ and $L$, respectively, show the upper and the lower $95 \%$ limits of agreement. The same scales are used in all figures to aid the visual comparison of biases and agreement intervals.

\section{DISCUSSION}

The evaluation and management of presbyopia are important because significant functional deficits can occur when the condition is left untreated. Undercorrected or uncorrected presbyopia can cause significant visual disability and have a negative impact on the patient's quality of life $\mathrm{e}^{(3)}$. Careful distance refraction provides the foundation for determining the management of presbyopia ${ }^{(3)}$. The optical correction for presbyopia is the sum of the refractive correction for distance plus the power of the near addition ${ }^{(3)}$. The nature of the distance correction itself influences the near addition ${ }^{(11)}$. Determining the addition in the presbyope is an essential clinical test for evaluating patients over the age of 40 years ${ }^{(7)}$. The results of these tests are usually refined according to the subject's preference in terms of image clarity and a comfortable near task distance ${ }^{(12)}$. The refinement stage will be shorter and easier if the tentative addition is determined as precisely as possible ${ }^{(6)}$.

In this study, the aim was to establish the level of agreement between tentative additions determined by four methods and the final addition. The results indicate that the mean differences between ten- 
Table 1. Agreement between tentative and final addition

\begin{tabular}{lcccc}
\hline & Mean & BIAS & p value & COA \\
\hline AAL & 1.925 & $-0.003(\mathrm{AAL}>\mathrm{AdF})$ & 0.9400 & \pm 0.725 \\
ADL & 1.803 & $0.100(\mathrm{ADL}<\mathrm{AdF})$ & 0.0003 & \pm 0.700 \\
BRA & 1.784 & $0.100(\mathrm{BRA}<\mathrm{AdF})$ & 0.0008 & \pm 0.550 \\
CCT & 1.941 & $-0.019(\mathrm{CCT}>\mathrm{AdF})$ & 0.5705 & \pm 0.577 \\
\hline
\end{tabular}

$\mathrm{AdF}=$ final addition; $\mathrm{COA}=$ coefficient of agreement $(1.96 \times$ standard deviation); Tentative add: $\mathrm{AAL}=$ one-half amplitude accommodation ( $\mathrm{AA}$ ) with minus lenses; $\mathrm{ADL}=$ one-third accommodative demand with positive lens; BRA= balanced range of accommodation with minus and positive lenses; $C C T=$ crossed cylinder test with initial myopisation
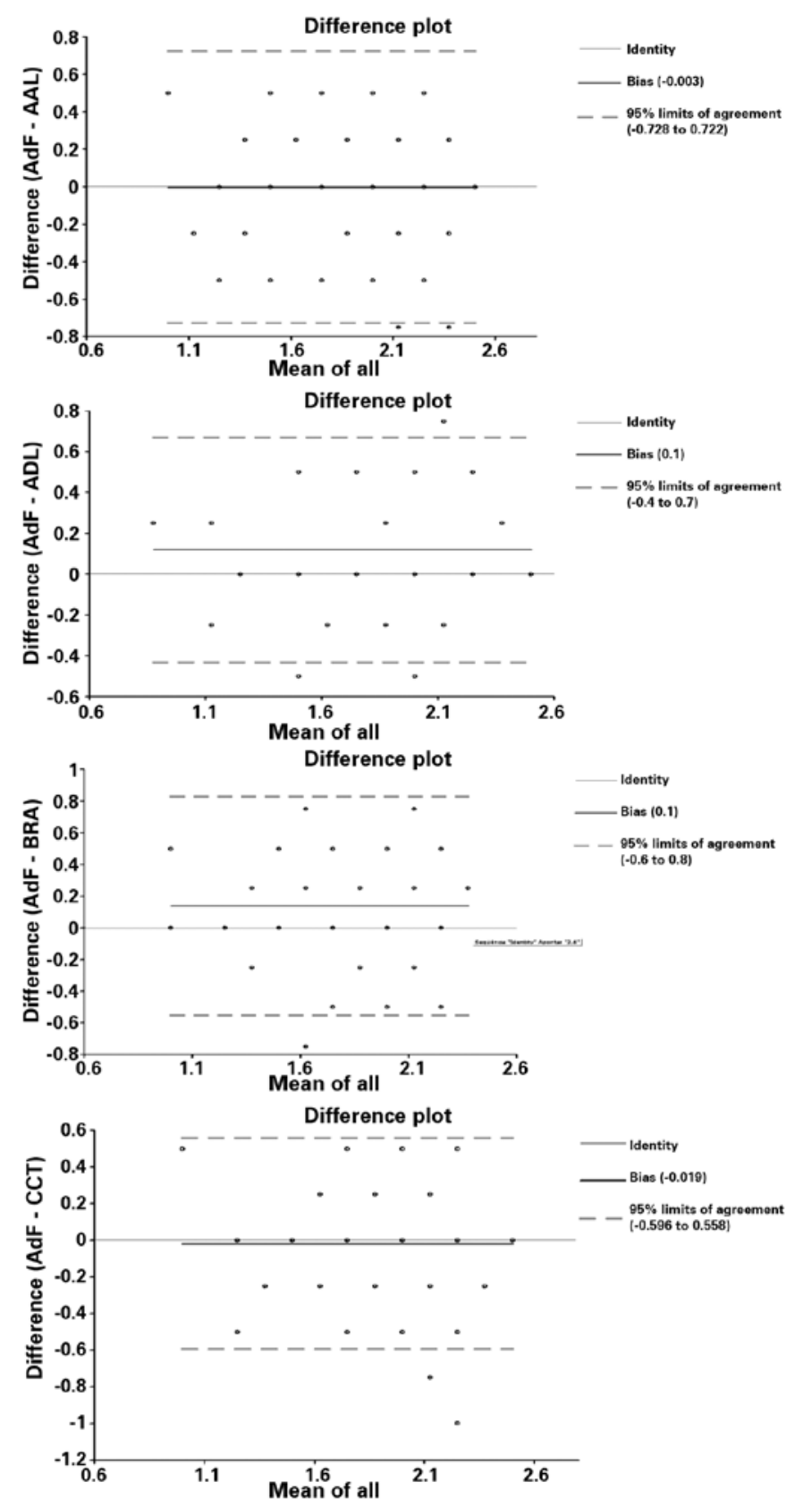

Figure 1. Plots for each subject of the difference between the tentative addition and the final addition (AdF-AdT) against the mean of both. The lines at $U$ and $L$, respectively, indicate the upper and lower $95 \%$ limits of agreement. tative and final additions were low for all the tests examined (less than $0.25 \mathrm{D}$ ). The agreement intervals ranged from about $\pm 0.50 \mathrm{D}$ to $\pm 0.75 \mathrm{D}$ (Table 1 and Figure 1). This means that the tentative addition provided by the AAL and ADL methods could be up to 0.75 D higher or lower than the final addition prescribed to the patient. Likewise the tentative addition provided by BRA and CCT methods could be up to $0.50 \mathrm{D}$ higher or lower than the final addition prescribed for the patient. The ADL based addition underestimated the addition ( $p=0.0003)$. Likewise, the BRA based addition underestimated the addition $(p=0.008)$.

The different methods used to determine tentative addition based on objective or subjective tests are not very reliable. Besides that, characteristics of the patient, such as visual needs, work habits, previous prescriptions may contribute to the different results, and consequently the wide COA obtained.

Antona et al ${ }^{(6)}$ compared final addition values with the tentative additions obtained using dynamic retinoscopy, amplitude of accommodation, age expected addition, fused cross cylinder without initial myopisation, fused cross cylinder with initial myopisation, near duochrome and the negative relative accommodation/positive relative accommodation (NRA/PRA) balance. For these authors the method that provided the result closest to the final addition power was the age-expected AA procedure. For them this test showed the narrowest agreement interval and the least bias.

As a result of this study the choice of method will be affected because all tests were similar in accuracy for the tentative addition, in other aspects, such as ease of application and time taken, the age expected addition method for assessing the tentative addition is an easy and effective test and it takes no time. A table of age-expected accommodative amplitudes can serve as a starting point for determining a near addition ${ }^{(13-15)}$. However, the values in the tables represent population averages, and the measured amplitude of accommodation for the individual patient may differ significantly from the age-group average. Measuring the amplitude of accommodation provides a more appropriate indication of the patient's accommodative ability and range of clear vision ${ }^{(3)}$.

These findings suggest that all the studied techniques displayed similar behavior and provided a tentative addition close to the final addition. Finally, the wide agreements detected here suggest that every tentative addition should be adjusted according to the particular needs of the patient.

\section{REFERENCES}

1. Koretz JK. Presbyopia. In: Levin LA, Albert DM, editors. Ocular disease: mechanism and management. China: Saunders Elsevier; 2010. p.258-66.

2. Bito LZ. Presbyopia. Arch Ophthalmol. 1988;106(11):1526-7.

3. Sousa SJ, Alves MR. Presbiopia. In: Alves MR, Polati M, Sousa SJ, editores. Refratometria ocular e a arte da prescrição médica. Rio de Janeiro: Cultura Médica; 2009. p.127-46.

4. Carter JH. Determining the nearpoint addition. N Engl J Optom. 1985;37:4-13.

5. Hanlon SD, Nakabayashi J, Shigezawa G. A critical view of presbyopic add determination. J Am Optom Assoc. 1987;58(6):468-72

6. Antona B, Barra F, Barrio A, Gutierrez A, Piedrahita E, Martin Y. Comparing methods of determining addition in presbyopes. Clin Exp Optom. 2008:91(3):313-8.

7. Kurtz D. Presbyopia. In: Brookman KE, editor. Refractive management of ametropia Boston: Butterworth-Heinemann;1996. p.145-79.

8. Michaels DD. Visual optics and refraction: a clinical approach. $2^{\text {nd }}$ ed. St. Louis: CV Mosby; 1980. p.571-4.

9. Bland JM, Altman DG. Measurement in medicine: the analysis of method comparison studies. Statistician 1983;32:307-17

10. Bland JM, Altman DG. Statistical methods for assessing agreement between two methods of clinical measurement. Lancet. 1986;1(8476):307-10.

11. Pointer JS. The presbyopic add. III. Influence of the distance refractive type. Ophthalmic Physiol Opt. 1995;15(4):249-53.

12. Abraham LM, Kuriakose T, Sivanandam V, Venkatesan N, Thomas R, Muliyil J. Amplitude of accommodation and its relation to refractive errors. Indian J Ophthalmol. 2005;53(2):105-8.

13. Patorgis CJ. Presbyopia. In: Amos JF, editor. Diagnosis and management in vision care. Boston: Butterworths; 1987. p.203-38

14. Millodot M, Millodot S. Presbyopia correction and the accommodation in reserve. Ophthalmic Physiol Opt. 1989;9(2):126-32

15. Hofstetter HW. A longitudinal study of amplitude changes in presbyopia. Am J Optom Arch Am Acad Optom. 1965:42:3-8. 